\title{
Relaciones de poder y memoria de un linaje. La intervención de la Casa de Moscoso en la Compostela de los siglos XIV-XVI
}

\author{
Territorial Power and the History of a Lineage. The Intervention \\ of the House of Moscoso in Santiago de Compostela \\ from the 14th to the 16th Century
}

\author{
Carlos J. Galbán Malagón \\ Universitat de Barcelona \\ cjgalban@gmail.com
}

[recibido 02/05/2015, aceptado 25/07/2015]

\begin{abstract}
RESUMEN
La ciudad ofrecía en la Baja Edad Media claras oportunidades para aquellos nobles que supieran situarse en el complejo juego de la política urbana y sus diversas instancias de poder. Para ello siempre se hace necesario contar con los apoyos sociales y físicos adecuados. La dinámica de enfrentamientos entre el Arzobispo de Santiago y el concello compostelano presenta un ejemplo inmejorable para valorar en su justa medida la inserción de la nobleza territorial en las relaciones de poder. Para abordar este caso se analizará la participación en la vida pública -también las revueltas urbanas- de la Casa de Moscoso tanto a través de su larga trayectoria de enfrentamientos con la Iglesia como mediante el estudio de su patrimonio urbano, incluyendo aquellos elementos relacionados con la creación de una memoria específica del linaje dentro de la ciudad.
\end{abstract}

Palabras Clave: Edad Media, Memoria y nobleza, Conflictividad urbana, Casa de Moscoso, Santiago de Compostela.

\section{RESUMO}

A cidade ofrecía na Baixa Idade Media claras oportunidades para os nobres que souberan situarse no complexo xogo da política urbana e das súas diversas instancias de poder. Para isto faise sempre necesario contar cos apoios sociais e físicos axeitados. A dinámica de enfrontamentos entre o Arcebispo de Santiago e o concello compostelán é un inmellorable exemplo para valorar na súa medida xusta a inserción da nobreza territorial nas relacións de poder. Para tratar este caso, analizarase a participación na vida pública -tamén as revoltas urbanas- da Casa de Moscoso, tanto desde a súa larga traxectoria de enfrontamentos coa Iglesia, como desde o estudo do seu patrimonio urbano, incluíndo aqueles elementos relacionados coa creación dunha memoria específica da liñaxe dentro da cidade.

Palabras Chave: Idade Media, Memoria e nobreza, Conflitividade urbana, Casa de Moscoso, Santiago de Compostela.

\begin{abstract}
During the Late Middle Ages, cities offered opportunities to those nobles who understood urban politics and its diverse aspects. This was made possible thanks to social and physical support. This stabilization of territorial nobility is perfectly exemplified by the constant confrontation between the Archbishop of Santiago and the city council. In order to analyse this, we will look into the role of a noble household -The Moscosos- regarding public life. We will include the family's constant confrontation with the Church and their urban heritage, including those elements related to the Moscosos' lineage within the city.
\end{abstract}

KEYwORDs: Middle Ages, Memory and Nobility, Urban Conflicts, Household of Moscoso, Santiago de Compostela.

Galbán Malagón, C. J. (2015): "Relaciones de poder y memoria de un linaje. La intervención de la Casa de Moscoso en la Compostela de los siglos XIV-XVI", Madrygal. Revista de Estudios Gallegos (Madr.), 18: 13-31.

SUMARIO: 1. Introducción. 2. La política compostelana y los Moscoso. 3. Patrimonio urbano y relaciones de poder. 4. Memoria y desmemoria de un linaje. 5. Conclusiones. 6. Referencias bibliográficas. 


\section{INTRODUCCIÓN}

Compostela. La imagen de una lejana ciudad santa destino final de las peregrinaciones europeas es sin duda una de las más sugestivas dentro del ámbito historiográfico del medievalismo actual. Asociada a esta imagen, la historia urbana de Compostela, la principal ciudad del Reino de Galicia, no deja de ser una anécdota marginal o una nota al pie en aquellos trabajos de profundo calado que analizan el fenómeno jacobeo desde una perspectiva más global. Tiende, pues, a dejarse de lado el análisis amplio de la topografía del poder dentro de la ciudad. Parece que esta consistía únicamente en el amplio palacio arzobispal bien guardado por la torre de la plaza, sede del poder de los prelados, la mole pétrea de la catedral y su claustro con diversas estancias, foco de expresión y poder del cabildo apostólico, y, finalmente, entre desvanes particulares y claustros mendicantes el concello de la ciudad repartía, según la ocasión, sus labores cotidianas ${ }^{1}$. Ambas instancias, la iglesia y el concello, en una tensión casi constante a lo largo del Medievo con notables estallidos de violencia que, incluso, llevan a plantear que Compostela es el modelo a imitar por otros núcleos urbanos tanto dentro como fuera del señorío arzobispal, particularmente durante la coyuntura irmandiña.
En este sentido y pese a su destacado protagonismo, la ciudad de Compostela no es en nuestra opinión un modelo de obligado cumplimiento. Casos como el de Ourense, por ejemplo, demuestran el enorme papel de la institución concejil como medio de vehicular el descontento de los grupos urbanos y los roces hacia la autoridad eclesiástica² ${ }^{2}$. No obstante, a finales del Medievo, más allá del habitual enfrentamiento entre la nobleza territorial y la alta jerarquía eclesiástica ${ }^{3}$, destaca el creciente protagonismo que la pequeña nobleza irá logrando en los conflictos urbanos como medio de capitalizarlos para lograr sus propios intereses ${ }^{4}$. Por ello, es necesario dedicar cierta atención a los medios para establecer las necesarias relaciones de poder que permitieron a la nobleza participar en la vida urbana en un espacio como Compostela en el que el control arzobispal debiera ser estrecho. Tanto en la topografía del tejido urbano -como evidencian la constante mejora de las fortalezas episcopales entre el XIV y el XV- como mediante la conformación de una red clientelar integrada por la nobleza y la burguesía urbana. En este sentido, entre los muchos linajes del territorio arzobispal hay uno que destaca por su rápido ascenso y fuerte presencia en los principales asuntos de la sede: la Casa de Moscoso5.

* Se emplean las siguientes abreviaturas de archivo: ACS (Archivo Catedralicio de Santiago), AGS (Archivo General de Simancas), AGEP (Archivo Genealógico Eduardo Pardo), AHDS (Archivo Histórico Diocesano de Santiago), AHUS (Arquivo Histórico Universitario de Santiago), ARCHV (Archivo de la Real Chancillería de Valladolid), ASPA (Arquivo de San Paio de Antealtares) y MP (Museo das Peregrinacións). Nuestro profundo agradecimiento tanto a los editores como a los evaluadores del artículo.

${ }^{1}$ Véase sobre la evolución posterior del concello compostelano frente a la autoridad arzobispal, López Díaz (1997: 44 y ss., en especial 58 y ss.). Sobre los espacios de poder en la red urbana gallega véase López Carreira (1999: 159 y ss.).

${ }^{2}$ El ejemplo auriense, entre otros, no deja de presentar similitudes con el compostelano; López Carreira (1991, 1999: 295-307).

${ }^{3}$ Ya analizado por Lojo (1991: 37 y ss.).

${ }^{4}$ En esto Santiago no es una excepción; véase una primera aproximación en Lojo (1991: 73 y ss.).

${ }^{5}$ Sobre la Casa de Moscoso se han abordado múltiples aspectos, como la trayectoria histórica de la casa y sus titulares, Galbán (2009), Framiñán (2004), Pardo de Guevara (2000), González (1996: 204207), Vázquez (1994); individuos ligados a la misma en Framiñán y García (2004) y Galbán (2011); véase García Oro y Portela Silva (2003). 
Se hace necesario, pues, dilucidar, por un lado, el grado de de participación de sus titulares en la vida urbana y, por el otro, la posible configuración de una topografía de poder alternativa a la de la Iglesia y, por qué no, el concello.

\section{LA POLÍTICA COMPOSTELANA Y LOS MOSCOSO}

Paradójicamente, se trata de un linaje con unos orígenes algo obscuros. Y aunque se conoce su relación directa con algunos vecinos de Santiago ya en el siglo XIII ${ }^{6}$, también es cierto que se trata de una familia muy emparentada con otros pequeños linajes de la Tierra de Santiago. Aunque hay miembros de la familia que ejercen dignidades eclesiásticas a lo largo del siglo XIV, la Casa no había logrado aún un papel significativo a nivel político. En realidad hasta las primeras décadas del siglo siguiente, con el servicio a algunos grandes nobles, como lo fue el Duque de Arjona, el linaje encabezado por Ruy Sánchez de Moscoso no logrará relevancia suficiente como para poder afianzarse territorialmente. Gracias a esta consolidación del patrimonio de la Casa a finales del XV los diversos titulares podrán capitanear con cierto éxito algunos de los más importantes enfrentamientos bélicos entre la nobleza y el arzobispado de Santiago.
No obstante, las relaciones previas con la iglesia, a lo largo del siglo XIV y principios del $\mathrm{XV}$, habían sido tremendamente positivas para la familia ${ }^{7}$. Esta cercanía con la principal autoridad señorial del Reino de Galicia facilitó un primer afianzamiento territorial materializado a través de la construcción de una fortaleza en Morgade, en las inmediaciones de su probable solar de origen, el pazo de Moscoso, cercano al camino que unía Santiago y la villa costera de Coruña, edificada gracias al consentimiento arzobispal ${ }^{8}$. No obstante, contamos con pocas referencias documentales de estos momentos, por lo que el patrimonio de esta rama laica de la familia sólo podemos conjeturarlo a partir del volumen de donaciones a la sede y de otras referencias indirectas.

Por otro lado, esta relación con Santiago podría explicar la intensa vinculación del linaje con algunas familias compostelanas, particularmente con los Do Campo(García Rodríguez 2012: 50-51, Pardo de Guevara 2009: 31, Vázquez 1994, López Ferreiro 1904: 30 y ss.). Una familia con una fuerte presencia en la vida pública compostelana durante el siglo $\mathrm{XIV}$, ejerciendo de representantes de la ciudad a las cortes o cargos públicos de relevancia ${ }^{9}$, llegando a la figura de Bernal Eanes do Campo, mayordomo de la ciudad aún en $1418^{10}$.

${ }^{6}$ Entre las figuras a destacar se hallan Pedro Vidal, su hija Mayor Pérez, Sancho López de Moscoso o incluso Juan Vidal do Camiño; véase Pardo de Guevara (2009: 36) y Castro (1996: 258).

${ }^{7}$ Respecto a los tres prelados de la casa, dos en Santiago y uno en Mondoñedo, véase Menéndez Pidal y Pardo de Guevara (2001) y Pardo de Guevara (2001: 75-81; 2006: 272). Hay, asimismo, varios canónigos como Gonzalo Pérez de Moscoso (ACS, S. 20/29), o el deán Gómez Arias. Sin olvidar en la primera mitad del XV a Teresa Sánchez de Moscoso y Berenguela de Moscoso, ambas monjas y abadesas de Santa Clara. Teresa figura como abadesa al menos hasta 1427, mientras que Berenguela aparece como procuradora del convento ya en 1432 y, como abadesa, en la década de los 50; incluso en 1460 aparece una Teresa Sánchez de Moscoso "a moça"; véase al respecto: Rodríguez (1993: 151, 190, 204, 219-221, 233, 254, 279, 283 286, 290), Gimeno (1996: 152), Justo y Lucas (1991: 404).

${ }^{8}$ González (1996: 188). Por otro lado, el titular de Morgade, Lope Pérez de Moscoso, es conminado junto a otros caballeros a no usurpar bienes del monasterio de Sobrado en 1380 (VV.AA. 1915: 237).

${ }^{9}$ En 1317 Pedro Eanes do Campo acude a Carrión, en 1369 Johan do Campo atestigua el señorío episcopal en un acta municipal; véase Sánchez (2008: 199), Pardo de Guevara (2006: 272, n. 46) y López Ferreiro (1895: 418).

${ }^{10}$ Sobre su condición de noble, amén de su servicio a la mitra, puede destacarse la presencia de afines y servidores propios (Rodríguez 1990: 137). 
Además de esta vinculación por sangre, parte de su patrimonio rural en el entorno compostelano iría pasando, desde principios del $\mathrm{XV}$, a manos del escudero Ruy Sánchez de Moscoso.

Pese a ello, no puede hablarse de que esta relación con la ciudad implique que los Moscoso sean un linaje burgués, sino que Santiago sirvió como punto de apoyo en sus aspiraciones señoriales en el momento justo en que sus vínculos con la iglesia se debilitaban a la par que su patrimonio territorial ${ }^{11}$.

El primer paso obligado en esta coyuntura para cualquier miembro de un pequeño linaje, incluso para uno que había contado con prelados ilustres, pasaba por el servicio al arzobispo del momento, Lope de Mendoza. Así, en 1402, dentro de la cámara del palacio episcopal de Santiago, el escudero Ruy Sánchez de Moscoso realizaba homenaje al arzobispo por la fortaleza de Xallas, estando presente su tío Bernal Eanes do Campo ${ }^{12}$. Casi una década después, los Moscoso iniciaban un pleito por unas propiedades en el entorno del camino inglés, ejerciendo el arzobispo como primer árbitro de la disputa $^{13}$. A ello pronto se le sumarían algunas cesiones de patrimonio eclesiástico en forma de tierras y derechos que mejoraron la situación de la familia (Rodríguez González 1995: 134; 1992: 155, 178).

Hay pues una presencia semipermanente en la ciudad, tanto a nivel patrimonial como personal, ya sea a través de los miembros del linaje como de individuos afines a la Casa. Pero las pretensiones familiares se vinculan principalmente a la obtención y consolidación de unos dominios rurales amplios y, si ello era posible, a sus fortalezas ${ }^{14}$. Este proceso de retroalimentación se ve en la constante intervención en la política urbana, pero siempre, insistimos, con una implicación territorial amplia; en esto, como en tantas otras cosas, es donde los Moscoso y la ciudad de Compostela, coincidían plenamente aunque, curiosamente, esta coincidencia implicaba una ruptura plena con el arzobispado.

Así, ya en 1421, Ruy Sánchez de Moscoso, como escudero y vasallo del rey, aparece en varias ocasiones en las actas concejiles conservadas. Primero como afín de un importante noble, Fadrique, Duque de Arjona y Conde de Trastámara, que escribe al concello, puesto que Ruy Sánchez le había referido que "los mercadores [...] de Santiago [...] se reçelan que algunas personas ynjustas en non debidamente por les faser mal [...] los querran prender e prendan e tomar algo de lo suyo sen rason e sen derecho" (Rodríguez González 1992: 256-257). Después presentando alguna carta real dirigida al propio concello, en cuyo texto el rey mina directamente el señorío episcopal. Finalmente, Ruy Sánchez acude nuevamente, y por cuenta propia, a una reunión concejil a reclamar la tavoa do selo de su tío Bernal, siendo al poco reconocido como vecino de la ciudad ${ }^{15}$.

Ha de tenerse en cuenta el momento que vive Compostela. Pese a los intentos del prelado Lope de Mendoza por controlar la formación de una hermandad en la ciudad acabó por

${ }^{11}$ Lo que debió suceder ya en 1397 con la muerte del noble Lope Pérez de Moscoso y el traspaso de parte de sus propiedades "do que perteençia ao bispo Gonçaluo e ao arçobispo don Rodrigo" en beneficio de la Iglesia de Santiago (ACS, 20/3).

12 ACS, IG 703/8, f. 64; ya conocido por López Ferreiro (1904, ap.: 6-8). Cabe destacar que Bernal Eanes do Campo aparece también junto al arzobispo en la fortaleza de A Barreira, en 1402, recibiendo homenaje por la fortaleza de Insúa (ACS, IG 703/31, ff. 157-160r).

${ }^{13}$ En López Ferreiro (1904: 28) se indica que el pleito se dirimió efectivamente, pero en realidad las partes enfrentadas recurrieron a nombrar a unos árbitros de su misma condición que poco después ratificarían la sentencia arzobispal (AHUS, Clero, Mitra, leg. 133, pieza 8; AHUS, Clero, Mitra, 133, pieza s/n).

${ }^{14}$ Sobre las fortalezas de la Casa véase Lema y Mouzo (1998), Galbán (2011b, 2009).

15 Véase Rodríguez González (1992: 156-157, 259-260, 264), Framiñán (2005: 328) y Galbán (2009: 152 y ss.). 
consentirla, dadas sus prolongadas ausencias de la sede y su implicación en los asuntos de la corte. La intervención real a favor del concello y la nobleza provocará una revuelta (14211422).

Aunque no debe magnificarse su papel en estos convulsos momentos, Ruy Sánchez encabezaría la lista de acusados que el arzobispo enviaría al Papa ${ }^{16}$. Pero esta participación parece derivar más del éxito de su servicio al Duque de Arjona y su cercana vinculación con los grupos urbanos que de un interés personal. Esto no implica que previamente la Casa de Moscoso no hubiera servido lealmente al arzobispado, pero Fadrique ofrecía la posibilidad de lograr un señorío propio casi al margen de la órbita arzobispal. Puesto que, además, Fadrique se apropió por la fuerza de algunas fortalezas de la Iglesia en 1424. Aunque según el documento eclesiástico alusivo a ello, era el arzobispo el que las había cedido por buena voluntad, claro que al poco de redactar la cesión y tras quejarse del rol de Fadrique $-\mathrm{y}$ Ruy Sánchez- en la revuelta urbana indica que se hizo por "miedo e themor e rreçelo" ${ }^{17}$. Esto sucedían entre enero y febrero, en mayo Ruy Sánchez recibía una pequeña donación territorial de Fadrique, al que acompañaría a la corte junto a otros caballeros ${ }^{18}$.

Poco después no será raro encontrar ocasionalmente a los Moscoso en la ciudad, sin que Compostela logre aparentemente un papel significativo en su estrategia señorial más allá de la derivada de sus relaciones familiares previas y el necesario cuidado de sus bienes. Lo que explicaría, además, la destacada relación posterior de la familia con el convento de Santa Clara a las afueras de la ciudad desde los caminos del norte ${ }^{19}$.

El patrimonio rural de la Casa acaparaba su atención, a veces en demasía. El prelado, Lope de Mendoza, no estaba en todo caso de brazos cruzados, atacando judicialmente las bases del señorío territorial de Ruy Sánchez y su hijo ${ }^{20}$. Esta ofensiva también se dio por medios violentos pues, en nuestra opinión, cabría situar aquí los sucesos de Angrois. En cierta ocasión, Ruy Sánchez pasó "cabo de la çerca de Santiago sin pedir tregua", saliendo entonces de la ciudad varios nobles del entorno arzobispal que le persiguieron y cercaron en un castro cercano, "matándole escuderos, y peones y cavallos, y firiéndole otros, y con una saeta le quebraron un ojo en la cabeça". Finalmente, tras una huida al abrigo de la noche el de Moscoso consiguió librarse del cerco (Aponte 1986: 153-154, 173).

A la altura de 1441, se asentaron los problemas con la mitra, recibiendo Ruy Sánchez el cargo de Pertiguero Mayor de la Tierra de Santiago en detrimento de Alfonso de Mendo$\mathrm{za}^{21}$, sobrino del arzobispo y uno de los atacantes de Angrois. El ejercicio de la Pertiguería Mayor, aunque con altibajos, será la principal pretensión de los sucesivos titulares del linaje y una de las marcas del éxito de sus estrategias de ascenso social y de su grado de libertad de acción frente a otros señores.

Mientras, los compostelanos obtenían el reconocimiento momentáneo de su condición de realenga. A diferencia de su antecesor, el nuevo

${ }^{16}$ Con cierta saña lo acusa también López Ferreiro (1904: 30, 36-38).

${ }^{17}$ AHUS, Colección Blanco Cicerón, Pergaminos nº 36.

${ }^{18}$ ASPA, Condado de Altamira, 3A1/74, f.4v. Cabe destacar su aparición en relación a Fadrique en la Crónica de Juan II de Fernán Pérez de Guzmán, en 1420, cap. 38, y 1429, cap. 23 (Vázquez 1994: 208, n. 7).

${ }^{19}$ Desde finales del XIV profesaron como monjas Teresa Eanes de Tudela, viuda de Fernán García do Campo, padre de Bernal Eanes do Campo, y al menos dos de sus hijas, Teresa Álvarez y María Eanes. (Rodríguez 1993: 123-124, 133-134, 185-187). Aunque estas relaciones sólo parecen haber tenido lugar durante la vida de Ruy Sánchez, hallándose aforamientos y acuerdos con el convento de este período.

${ }^{20}$ AHDS, Fondo General, Catálogos, n², cuaderno " $\mathrm{n}$ (37".

${ }^{21}$ Villamil (1873: 59-63), Lojo (1991: 83) y Galbán (2013: 139-143); véase Justo y Lucas (1991: 431-432). 
prelado compostelano, Álvaro de Isorna, con calma consiguió ver reconocido su señorío y aplacar a los burgueses y a la nobleza. Era el de Isorna un personaje vinculado a varios de los linajes de las tierras arzobispales como Isorna, Gres o Xunqueiras y con un papel destacado durante el primer levantamiento irmandiño de 1431. De tal modo, y aunque hubo algunos roces sobre el cobro de rentas y derechos en las tierras arzobispales ${ }^{22}$, no parece que hubiera grandes enfrentamientos con la nobleza. De hecho, Ruy Sánchez mantuvo la pertiguería ${ }^{23}$. Pero la muerte de este hábil prelado dio paso al nombramiento de Rodrigo de Luna. Entre medias Ruy Sánchez intentó obtener del cabildo el control de la torre da praza ${ }^{24}$.

En principio no hubo grandes cambios. En 1456 fallecía Ruy Sánchez y al año siguiente su hijo, Rodrigo de Moscoso, tomaba posesión de la Pertiguería Mayor ante el arzobispo (López Ferreiro 1904, ap.: 112-114). No obstante, Rodrigo de Luna intentó mejorar su posición política manu militari ${ }^{25}$; incluso podría pensarse que jugaba sobre seguro: Rodrigo de Moscoso padecía lepra e hizo testamento en febrero de 1458. Aunque el destino le deparaba una sorpresa al prelado, en marzo los caballeros de la Tierra de Santiago, encabezados por el Pertiguero, se negaron a atender el llamamiento episcopal para acudir con el arzobispo a Écija a las campañas de la monarquía ${ }^{26}$.

Pese a los graves problemas con la nobleza Rodrigo de Luna habría de ausentarse de Compostela aunque, sin saberlo, lo hacía para siempre. En junio de este mismo año, ya fallecido Rodrigo de Moscoso, su viuda,
Juana de Castro, y su primogénito, Bernal Yáñez, firmaban junto a otros nobles y los representantes de Santiago, Muros y Noia la conocida como Hermandad de Antealtares (Pallares y Portela 2002: 91; Sánchez 2010). Este hermanamiento implicaba que los señores no socavarían el gobierno y vida urbanos. Pedro Álvarez Osorio, nuevo y ambicioso Conde de Trastámara aglutinaría la revuelta contra el prelado. En el verano de 1459, esta heterogénea alianza asediaba la fortaleza de Rocha Forte. Dentro de la ciudad los revoltosos, ignorando el interdicto eclesiástico, obligaban al cabildo a celebrar los oficios con las puertas abiertas y rezar las horas. En diciembre del mismo año, parte del cabildo se traslada a la iglesia de Santiago de Padrón junto a la fortaleza de Rocha Branca (VV.AA. 1931: 209).

La implicación directa de los Moscoso en este conflicto parece clara. Aparentemente estaban actuando otra vez como afines de un gran señor. En cambio, que actuaran junto al Conde de Trastámara no los convierte de facto en sus afines. En nuestra opinión el dilema de los Moscoso ya no era servir o perecer (cf. Péricard-Méa 2010: 168-170), sino que este enfrentamiento los posicionara como una Casa fuerte e independiente en el concierto nobiliar gallego. Muertos Ruy Sánchez y Rodrigo, sólo quedaban sus hijos, Bernal Yáñez y su hermano, Álvaro Pérez, como líderes del linaje, junto a su madre Juana. Pero había otro Moscoso, Lope Sánchez de Ulloa el mozo, heredero del malhadado primogénito de los Ulloa, Vasco López y de Inés de Moscoso. El arzobispo, tío del propio Vasco López de Ulloa, había

\footnotetext{
22 Véase ACS, S. 15/79.

${ }^{23}$ Por ejemplo, en 1444, como caballero y pertiguero mayor acompaña a su mujer a Ribadavia para realizar un préstamo a la Condesa de Santa Marta, Fernández Suárez (2002: 368).

${ }^{24}$ Para López Ferreiro (1895: 460-461; 1904:170-171) y López Díaz (1997: 59), que lo dan por conseguido, se trataría de algo inusitado; no obstante había algún precedente en la propia sede (Galbán 2013: 133, 142, n. 49).

${ }^{25}$ ASPA, Condado de Altamira, 4, f. 29r (Galbán 2011c: 164-166).

${ }^{26}$ La terminante negativa fue leída y presentada en la propia catedral por afines de la Casa de Moscoso (ACS, LD 19/13, ff. 2-5r).
} 
reconocido derechos a la tenencia de las fortalezas que Vasco tenía de la iglesia tanto a la Casa de Ulloa como a la de Moscoso motivando varios enfrentamientos en medio de una guerra generalizada con la sede. Los Moscoso tomarían las fortalezas y ocuparían brevemente Rocha Branca ${ }^{27}$. Mientras tanto, una coalición señorial fracasaba ante los muros de Rocha Forte y el propio arzobispo, desde Salamanca, ofrecía garantías territoriales a Bernal y a Juana de Castro.

En este orden de cosas, y desde su comodidad en la propia Compostela, Bernal Yáñez cambió de bando enfrentándose al Conde de Trastámara que ambicionaba no solo Compostela sino los dominios de los Moscoso en la tierra de Trastámara (Aponte 1986: 174-175; McKenzie 1984: 67). Así, los Moscoso pasarían a apoyar la campaña militar del prelado organizada desde la misma Rocha Branca. Pero Rodrigo de Luna, fallecería en julio de 1460 , siendo enterrado en la cercana colegiata de $\operatorname{Iria}^{28}$.

En este estado de cosas es cuando se produce el nombramiento de Alonso de Fonseca como arzobispo de la sede. Sin incidir en las implicaciones de esta elección, sería su experimentado tío, también un Alonso de Fonseca, arzobispo de Sevilla, quien jugaría con habilidad sus cartas para recuperar la sede ${ }^{29}$. La documentación de estos momentos iniciales no es todo lo clara que nos gustaría pero baste decir, que tras hábiles compromisos pudo tomar posesión efectiva y pacífica de la sede.

Es justo en este instante cuando la Casa de Moscoso ve colmadas sus expectativas, la pertiguería y el permiso para construir una nueva fortaleza en las inmediaciones de Santiago, casi como un reflejo de lo sucedido en Morgade el siglo anterior: la fortaleza de Altamira. En la primera referencia documental datada en la fortaleza se menciona específicamente el respeto a los derechos eclesiásticos tocantes a una pequeña propiedad en las inmediaciones de la fortaleza ${ }^{30}$. Esta consolidación sólo fue aparente. Los enfrentamientos con su sobrino llevaron a Alonso de Fonseca I a abandonar la inestable sede compostelana y volver a Castilla.

La llegada del joven Alonso de Fonseca II, no pudo resultar más ruidosa. Tal vez la necesidad de contar con un entorno de su confianza despertó las suspicacias de la nobleza territorial y los burgueses compostelanos. Fonseca denunció los acuerdos con la Casa de Moscoso lo que conllevó su rápido secuestro en la apacible villa costera de Noia ${ }^{31}$.

Con este total descabezamiento de la sede, se procedió a atacar las fortalezas eclesiásticas en Compostela, la Torre da Praza y la catedral, en su interior la madre de Fonseca, Catalina de Fonseca, junto a su otro hijo, Luis de Acevedo, buscaba disponer de las riquezas capitulares para recuperar a su hijo, cuestión que dividió al cabildo:

en defensión della e de la dha. cibdad e del dho. Arzobispado contra Bernaldianes de Moscoso, e D ${ }^{a}$ Juana de Castro e Alvar Pérez de Moscoso e Suero Gómez e D. Fernando e Lope Pérez e las otras gentes de la dha cibdad e fuera della, que han tenido e tienen preso al dho. Sr. Arzobispo e cercada la dha. Iglesia e torres de la plaza por dos veces... lo quales aun

\footnotetext{
${ }^{27}$ Diferimos, pues, de la versión de Fernández Abella (2014: 229-230), puesto que el acuerdo con el arzobispo se hizo con los Moscoso desde una buena posición negociadora y no por el fracaso en Rocha Forte.

${ }^{28}$ Es de referencia obligada Cendón (1997: 203-220).

${ }^{29}$ AGS, Cámara de Castilla, Personas, leg. 10-2, ff. 399-402.

${ }^{30}$ AHUS, Clero, Mitra, leg. 133, pieza 22, f. 1. Sobre la datación de Altamira, véase Galbán (2009: 160-161).

${ }^{31}$ Un caso similar sufriría el obispo de Tui, Diego de Muros, a manos de Pedro Álvarez de Soutomaior, como señala Lojo (1991: 41-42).
} 
ahora residen e se esfuerzan de estar faciéndonos toda la guerra de sangre e fuego. (Couselo 1926: $123-126)^{32}$

En contextos urbanos no es raro el asalto violento de las sedes físicas del poder señorial, tanto por su valor puramente estratégico para dominar efectivamente el núcleo urbano como por su valor simbólico, base física de la autoridad $^{33}$. De tal modo, la pervivencia de diversos relatos sobre los hechos permite valorar en detalle la participación de los Moscoso en el conflicto. Por una parte, de todos los mencionados por Catalina de Fonseca, cuatro de ellos son miembros proactivos de la Casa, Bernal, Álvaro, su madre Juana y su cuñado, Lope Pérez, y un quinto en discordia, Suero Gómez, se alió frecuentemente con ellos. Para los miembros del cortejo de León von Rosmithal, por otra parte, era Bernal el que capitaneaba a los compostelanos sin mencionar su Casa. La confusión se produce probablemente por la inclusión de los Moscoso en la Gran Hermandad gallega de 1465, siendo los sucesos de Santiago una evidencia clara del estallido irmandiño y no un precedente de 1467. Incluso tiempo después, con algo de mala intención y resentimiento, el chantre de la catedral, Juan de Melgarejo, declararía que el enfrentamiento se debía en realidad a que Bernal quería ser arzobispo "porque hera impotente para mujeres y con formas y maneras esquisitas matara a su mujer para efetuar su propósito" (Rodríguez González 1984: 290). Lo llamativo de esta justificación es que, en realidad, la Pertiguería Mayor pasaría ya en 1466 de Bernal, muerto por las heridas del asedio, a su hermano Álvaro Pérez, en un amplio acuerdo con el arzobispo se menciona el juramento de los nobles a la hermandad (Portela et alii 2004: 102, 105-106, 111; Rodríguez González 1984: 343).

Este acuerdo conllevaba, dato relevante, la entrega de Rocha Forte a los Moscoso. En teoría se entregaría la fortaleza eclesiástica más cercana a Compostela, lo que convertía el territorio en torno a la fortaleza de Altamira en un espacio ajeno a posibles intervenciones de la Iglesia. Este hecho no ha despertado apenas interés en la investigación, puesto que el tópico historiográfico sobre las destrucciones irmandiñas daría aparente cuenta de la destrucción de la Rocha, pero se trata en realidad de un momento capital para la Casa. Las alusiones al cumplimiento del acuerdo son indirectas pero parecen confirmarlo:

DeRibaron la fortalesa y casa de la Rocha del Arçobispo de Santiago, que la tenja el fijo de Rodrigo/de Moscoso, no la podiendo tomar, de/ Ribaronle la fortalesa e casa de Al/tamjra, que era suya. (Lope García de Salazar 1984: 418)

Así, los Moscoso tuvieron el control, al menos nominal, de la fortaleza, si bien en el contexto irmandiño esto sería durante breve tiempo. Por lo que resulta impepinable que la Rocha Forte, "candela e hermosa joia para la iglesia de Santiago", sería entregada por los Moscoso, que, como vimos, eran parte de la Hermandad, a los irmandiños y por una vía no necesariamente violenta, pudiendo derribarse después con o sin su consentimiento ${ }^{34}$. A ello se suma la muerte de Álvaro Pérez de Moscoso y Lope Pérez de Mendoza a causa de una epidemia -o de la venganza divina, según un cronista del momento.

${ }^{32}$ Los viajeros que llegaron a Compostela vieron: "un poderoso señor había acampado delante de la Iglesia. Con él estaban los de Santiago y tenían la Iglesia enteramente cercada, tirando tiros [...] y contestando los de dentro. Y el señor y la gente de la ciudad tenían prisionero en un castillo, fuera de la población, al Obispo [...] Habían atacado la Iglesia el mismo día de Santiago, el señor enemigo del obispo a la cabeza de los de la villa"; véase VV.AA. (2008: 256-263), Péricard-Méa (2010: 169-171), Pardo de Guevara (2006b: 496), Pallares (2002: 97-99), Vaamonde (1917: 239).

${ }^{33}$ Los asaltos a los edificios episcopales de Ourense son una buena muestra de ello (López Carreira 1998).

${ }^{34}$ Ya señalamos este posible orden de acontecimientos en Galbán (2011d: 88-89, 2009: 158-159), pese al relato de testimonios posteriores en el Pleito Tabera-Fonseca al que alude Fernández Abella (2014: 240-243), ya sistematizados y analizados críticamente por Presedo (2006), indicando, por ejemplo, que el alcaide arzobispal de la Rocha estaba en A Barreira. 
El descabezamiento de los Moscoso, llevó a Fonseca a intentar controlar lo que quedaba de su Casa, intentando apropiarse y administrar su patrimonio. Al poco, el joven Lope Sánchez de Ulloa, sobrino de Bernal y Álvaro, como nuevo jefe de la Casa se quejaba ante los jueces del desmantelamiento patrimonial que sufría a manos del prelado (García Oro y Portela Silva 2003: 545-548). El escarmentado arzobispo pudo pensar en devolver el daño sufrido aprovechando la estabilización de la política compostelana pero, de hecho, era la mejor oportunidad para acabar definitivamente con el punto muerto al que había llegado su relación con los Moscoso y sus afines.

No es lugar este para narrar la rápida campaña que planificó Fonseca, aunque pese a su prometedor inicio no tuvo en cuenta la dilatada relación entre las Casas señoriales gallegas -particularmente entre los Moscoso y los Andrade- que reaccionaron al unísono, plantándole cara al arzobispo en las inmediaciones de la principal fortaleza de los Moscoso, Altamira, en 1471, en la braña de Augapesada ${ }^{35}$. Sólo es necesario destacar la completa derrota de las tropas arzobispales, se perdió el Pendón de Santiago y huyeron del campo el prelado y su hermano. Aunque, en uno de esos peculiares giros de la historia compostelana, el pendón reapareció una noche en pleno altar mayor de la catedral de Santiago como si nada hubiera pasado, mostrando que incluso en plena guerra la nobleza contaba con la capacidad de entrar en la ciudad a voluntad ${ }^{36}$.

Alonso II de Fonseca necesitaba un pacto que lo afianzase en el poder, comportamiento habitual de sus predecesores. Este se logró mediante un matrimonio, Aldonza de Acevedo, sobrina de Fonseca, se casaría con Lope Sánchez de Moscoso. A cambio, se consolidarían como feudos de la Iglesia la torre de Cira y otras propiedades, así como la pertiguería (Aponte 1986: 191-192). No obstante, y a instancias de Fonseca, se produjo un intento fallido de secuestrar al conde en Cira. Al mismo tiempo, Lope Sánchez obtenía en 1475 confirmación real del título de Conde de Altamira, con un mayorazgo asociado. Cuatro años después el conde y varios de sus afines eran excomulgados ${ }^{37}$.

Por otro lado, el arzobispo, aprovechando una deuda judicial del Conde de Altamira, actuó con eficacia en contra de otros miembros de su parentela, atacando el patrimonio de Urraca de Moscoso y su hijo Rodrigo, intentando lograr por vía judicial lo que no había alcanzado antes por las armas, la alianza o la censura eclesiástica. Al carecer Lope Sánchez de herederos directos de su título y mayorazgo, se estaba erosionando el patrimonio de la Casa entendiendo que, al darse cierta interdependencia económica entre los miembros de la Casa y el titular, en el fondo sería Lope Sánchez el que debería compensar la pérdida de recursos ${ }^{38}$. Así, en las subastas de propiedades para satisfacer la deuda Fonseca llegó a facilitar dinero propio para que se comprase, aunque siempre a los precios más bajos posibles.

El contexto político gallego se iría serenando. Aunque el entendimiento del arzobispado y los Moscoso no estaba dentro de lo habitual, quedaría definitivamente truncado por el suicido de Aldonza en la propia Compostela en $1491^{39}$.

${ }^{35}$ Galbán (2011c: 168-175); cf. Carrasco (2015: 37 y ss.). Véase Fernández Abella (2014: 245-246).

${ }^{36}$ Véase Sánchez (2010: 107), González (1996: 70), Vázquez (1994: 216-217), Aponte (1986: 181186), Rodríguez González (1984: 218) y Portela (1957: 79-83).

${ }^{37}$ ACS, S. 22/33.

${ }^{38}$ AGS, Registro General del Sello, 1488, 10, f. 38 (Presedo 2008: 201, n. 36). Sobre el funcionamiento en bloque del patrimonio de los Moscoso, véase Galbán (2011: 239).

${ }^{39}$ ACS, IG 705 / 59, ff. 411-412. Aunque este suicidio, por ahorcamiento, es de sobra conocido por los investigadores gracias a Aponte (1986: 202), suele datarse erróneamente en 1504 (cf. García-Fernández 2013: 349, n. 21). 
Aunque desconocemos los motivos precisos que condujeron a Aldonza, el posible aislamiento dentro de la Casa de su esposo -en la excomunión que habían sufrido los Moscoso en 1479 se maldecía específicamente a "las mugeres con que dormieren e el fruto que dellas [...] salier"-, tanto por la inutilidad de la frustrada alianza matrimonial como por la propia persona y carácter de Lope Sánchez, y el extrañamiento forzoso respecto a sus familiares parecen los motivos más plausibles que llevarían a Aldonza a quitarse la vida ${ }^{40}$. Un caso similar lo tendríamos en Maior de Soutomaior, segunda esposa de Ruy Sánchez de Moscoso, a la que en su momento los Moscoso dificultaron acceder a los bienes legados por vía testamentaria, aunque ella sí pudo reintegrarse a su linaje de origen ${ }^{41}$.

Con todo, la Casa de Moscoso seguiría presente con fuerza en la ciudad, a través tanto de sus escuderos, criados y servidores, algunos de ellos compostelanos que llegarían a intervenir por cuenta propia en la vida política de la ciudad como regidores o alcaldes ordinarios ${ }^{42}$. Claro está, las disputas y roces seguirían y no son raras las noticias de ataques esporádicos y violentos contra los respectivos afines aún en las primeras décadas del XVI cuando agentes arzobispales entraron en el palacio condal y se apropiaron de cierta documentación ${ }^{43}$. Último choque digno de tal nombre puesto que a par- tir de estos momentos la vía judicial cobraría fuerza y normalmente en favor de la Iglesia y en detrimento de los Moscoso ${ }^{44}$.

\section{PATRIMONIO URBANO Y RELACIO- NES DE PODER}

Los Moscoso, como se ha expuesto, no eran un linaje de raíz urbana. Hemos detallado su trayectoria y participación en los principales acontecimientos del período final de la Edad Media. Sin embargo, esto debería reflejarse en un amplio patrimonio inmobiliario que permitiera al linaje intervenir de un modo cercano en la vida compostelana estableciendo asimismo una pequeña red de afines más que un bando urbano.

Aunque desconocemos la entidad total de sus posesiones dentro del núcleo urbano, es posible rastrear algunos bienes que pasaron a la familia, en especial a manos de los eclesiásticos. Así, ya en 1237 un tal Sancho López de Moscoso posee varios bienes en la Rúa da Pena, probablemente origen de unas casas con huerta que, como otras ingentes propiedades del obispo Gonzalo de Moscoso, pasarían a manos de la sede compostelana a lo largo del $\mathrm{XIV}^{45}$ (Rodríguez 1993: 57).

En 1400, la última voluntad del muy letrado canónigo Ruy Sánchez de Moscoso ${ }^{46}$, informa con detalle de su vinculación con

\footnotetext{
${ }^{40}$ Aunque, entre las escasas noticias sobre ella, se conserva una serie de pagos a modo de pensión anual ordenados por el arzobispo entre 1481-1483, montando un total de 45000 maravedíes, y la entrega de unas marranas por parte del tesorero arzobispal algunos años después (Vázquez Bertomeu 2002: 212, 243).

${ }^{41}$ ACS, P. 001, ff. 279-283r y ACS, IG 703/27, ff. 130-131r. Sobre la participación de Maior en su casa de origen, véase Vila-Botanes (2010: 466-472).

${ }^{42}$ Deben destacarse casos como el de Francisco de Reinoso, el de Martín Romeu o el de Lopo de Rendal; véase el análisis y trayectoria sucinta de los afines de la Casa de Moscoso en Galbán (2011: 254, n. $111 ; 255$ y ss.).

43 AGS, Cámara de Castilla, Personas, leg. 120, doc. 134 (Olivera 1999: 300-301; Aponte 1986: 200).

${ }^{44}$ No obstante, la autoridad episcopal no dejará de chocar judicialmente con el concello (López Díaz 1997: 111 y ss.).

45 Si bien aún en 1393, parte de la propiedad estaba aforada y en manos de la viuda de un Moscoso (Manso 1983: 102; García Oro y Portela Silva 2003: 77).

${ }^{46}$ Tras el prólogo latino de su testamento, dice: "Esto abasta [...] en memoria da escola en que foy criado e ensenado" (García Oro y Portela Silva 2003: 85).
} 
el resto de su linaje, en las personas de Ruy Sánchez y Rodrigo de Moscoso, pero también nos habla de la fundación del hospital de San Miguel en la Rúa do Camiño, fundación que se ha venido destacando desde antiguo por llevar aparejada la existencia de una biblioteca en el mismo "para hestudio dos peregrinos e romeus clerigos e leigos leterados" así como un mesón llamado Santo Espíritu ${ }^{47}$. Al margen de esto a finales del siglo la Casa de Moscoso poseía en la misma calle casas y palacios ${ }^{48}$ (Fraga 2000: 154-155).

Quitadas las propiedades de origen familiar, el núcleo principal de las posesiones urbanas se heredan de los Do Campo ${ }^{49}$. Especial relevancia tiene la casa con torre que esta familia poseía en la Praza do Campo, y que tenía origen en un inmueble del cabildo ${ }^{50}$. Este sería el principal edificio de los Moscoso a lo largo del $X^{51}$, ubicado en una posición inmejorable, en un punto clave de la vida pública -lugar de lectura de los pregones- $\mathrm{y}$, por tanto, en una posición privilegiada tanto para visibilizar la posición social lograda por el linaje como para que sus enemigos pudieran atacarlo físicamente.
Hablando en puridad, esta sería la primera residencia condal en Compostela, como atestigua el inventario de bienes del I Conde de Altamira, en 1504, que alude a un edificio torreado, con cámaras, sala cuadra y bodega (García Oro y Portela Silva 2003: 461-467). La centralización burocrática de los asuntos del Condado de Altamira en esta casa ${ }^{52}$, levantó las suspicacias de la iglesia, ya que se cobraban rentas y despachaban asuntos que podrían corresponder al arzobispado como, y siguiendo la versión eclesiástica, el ejercicio de la justicia.

Existen otras propiedades urbanas en otras zonas. Cabe destacarlas pues aunque apenas aparecen reflejadas documentalmente, resultan llamativas por su entidad a nivel patrimonial, aunque es muy complicado conocer su origen. A finales del XIV, Isabel Eanes mujer de Gonzalo Pérez de Moscoso realizaba testamento yaciendo "em huna cama, en na cámara das casas da sua morada" en la Rúa Nova (Manso 1983: 101). El recuerdo o la relación con esta zona de la ciudad pudo conducir a sus descendientes a acumular parcialmente propiedades en ella. Así, los Moscoso adquieren

${ }^{47}$ Parte de los libros litúrgicos ya debían venir de las donaciones que en 1326 había hecho a sus familiares el obispo de Mondoñedo (García Oro y Portela Silva 2003: 80-81). Sobre el hospital y sus alrededores, véase Valdés (2011: 155); sobre el testamento, Barreiro (1888). A finales del siglo XV los regidores de la ciudad eran patrones de este hospital (Sánchez 2010: 180).

${ }^{48}$ Urraca también había hecho mandas para la fábrica de Santa María do Camiño (AGEP, Moscoso, 12); véase Manso (1985: 52), García Oro y Portela Silva (2003: 96), Sánchez (2010: 180).

${ }^{49}$ No sabemos si todo el patrimonio inmueble dentro de la ciudad pasaría directamente a los Moscoso. Precisamente, porque no conocemos con exactitud todos los edificios, es posible que un pequeño palacio en la Rúa de San Miguel dos Agros les perteneciese. Hay algunas evidencias tanto en los edificios conservados como en la documentación (Lucas 1999: 384, 422).

${ }^{50}$ Cabe destacar la decoración de este edificio, en la arquería tenía varios capiteles figurados, y en su piso superior adornado campaban los escudos de Moscoso y do Campo (Barreiro 1889, Gimeno 1996: 160, García Oro y Portela Silva 2003: 478). Sobre el origen y ubicación de las propiedades capitulares en la plaza como la "domus de Campo" que un canónigo legó a la sede en 1245, véase VV.AA. (1901: 235); una visión de las propiedades, casas y tiendas en este espacio, en Rodríguez (1990: 105-107).

${ }^{51}$ Probablemente las "casas de morada" de Ruy Sánchez de Moscoso a mediados del XV (AHUS, Clero, Mitra, leg. 133, pieza 16) y lugar de redacción del testamento de Urraca de Moscoso; véase Valdés (2011: 157-158). Esta vinculación podría explicar la exclusión patrimonial de Maior de Soutomaior, al quedar la casa en manos de Juana de Castro a la muerte de Rodrigo de Moscoso, ya que Maior de Soutomaior tendría derecho a parte del ajuar de las casas de Santiago.

${ }^{52}$ AHUS, Protocolos Notariales, S-55, ff. 20r-21r y S-62, ff. 89-91; ASPA, Condado de Altamira, 6F3/718; ACS, P. 001, f. 109. 
unas casas de morada en la Rúa do Vilar, que probablemente están en uso a mediados de la centuria siguiente y que también tuvieron cierto protagonismo como marco de varios acuerdos $^{53}$. Asimismo, en la Rúa do Franco, a la altura de Fonte do Franco, había un palacio, una torre y otras propiedades anexas. Al parecer no tuvieron importancia para el linaje como lugar de proyección señorial, de hecho la noticia más antigua que se ha hallado es su aforamiento a un cantero (García Oro y Portela Silva 2003: 513). Aunque por las descripciones documentales sabemos que no eran meras casas de labranza, sino que se trataba de una torre y una amplísima huerta pegada a unos palacios ya arruinados a juzgar por su estado en unos aforamientos a finales del siglo ${ }^{54}$. Aunque estos documentos establecían el derecho de que el linaje recuperase y reutilizase este amplio complejo, ello nunca tendría lugar, y podemos conjeturar que ya en las primeras décadas del XVI, cuando se están realizando obras de importancia en los colegios inmediatos, sólo subsisten como parcelas aforadas a particulares ${ }^{55}$, si bien es posible encontrar alusiones posteriores a parcelas y bienes en la zona resulta harto difícil establecer una correlación exacta ${ }^{56}$. No obstante, la importancia del condado, su mayor racionalización organizativa $\mathrm{y}$, tal vez, la necesidad de adaptarse a los nuevos gustos sin los condicionamientos de unos viejos e incómodos edificios conllevó la búsqueda de un espacio idóneo a las necesidades de los condes. Por ello, en 1535 se adquieren las extensas propiedades del resentido y ya difunto chantre Juan de Melgarejo. Ubicadas en el espacio inmediato a la iglesia y cementerio de San Fiz de Solovio y pegadas a la muralla de la ciudad ${ }^{57}$. Se trataba de unas casas grandes con varios edificios menores y una huerta arbolada, con una fuente de agua, pero sin contacto físico con otros edificios, esto es, una arquitectura idónea para una nobleza que buscase implementar unos gustos ya propios del Renacimiento y administrar sus propiedades, pese a los roces jurisdiccionales ${ }^{58}$. La relación de los condes con Galicia debió hacerse menos fluida, como parece indicar el desmantelamiento parcial del edificio; incluso hubo que encargar a Domingo de Andrade una importante obra en el mismo de cara a prepararlo para una visita condal ${ }^{59}$. No obstante, la administración y los archivos condales permanecerían en el edificio hasta mediados del XIX, en que pudo sufrir un incendio previo a su desmantelamiento ${ }^{60}$.

${ }^{53}$ En agosto de 1452 Ruy Sánchez, como juez árbitro, junto a otros nobles, atestigua en Santiago el acuerdo entre Diego Pérez Sarmiento y Álvaro Páez de Soutomaior “en las casas de Ruy Sanches [...] de Moscoso, Pertigero Mayor de Tierra de Santiago, que son en la dicha çibdad en la rua del Villa" (Fernández Suárez 2002: 388). Tal vez las mismas casas en que “pousa” Bernal Yáñez de Moscoso en 1459 cuando otorga un poder a su madre para que negocie con el arzobispo (ACS, IG 703/27, ff. 130-131r); véase Rodríguez (1993: 214, 222) y García Oro (1987, 2: 34). No sabemos si esta propiedad pudiera tener relación con esas "casas e torres da rua do Bilar" que poseía en 1329 Vasco de Ulloa (VV.AA. 1915: 146). Cf. García-Fernández (2013: 362, n.49), que limita las propiedades a las casas do Campo y a estas del Vilar.

${ }^{54}$ ACS, P. 002 ff. 259-260 y ff. 260v-261.

${ }^{55}$ AHUS, Protocolos Notariales, S-169, ff. 238r-239v; AHUS, Protocolos Notariales, S-169, ff. 262(bis) r-263(bis)r; AHUS, Protocolos Notariales, S-55, ff. 18r-19v. Véase García Oro y Portela Silva (2003: 508).

${ }^{56}$ Por ejemplo, en el siglo XVIII hay una casa que daba a la actual Praza do Toural (ASPA, Condado de Altamira, 3B2/150, f.1r).

${ }^{57}$ AHUS, Protocolos Notariales, S-62, ff. 89-91, 92-94r y 94. Sobre el edificio y su evolución, Fernández González (2009).

${ }^{58}$ ASPA, Condado de Altamira, 3A2/93 (A y B), B, f. 2v.

${ }^{59}$ APDP, Fondo Especial 1-Familia Caamaño, 1223/3, f. 27; lo que matiza lo señalado por Fernández González (2009: 160).

${ }^{60}$ ASPA, Condado de Altamira, 7/917. 


\section{MEMORIA Y DESMEMORIA DE UN LINAJE}

Como parte final es obligado resaltar la topografía de la memoria del linaje dentro de la ciudad. Aunque con cautela, puesto que, por un lado, están los lugares vinculados al linaje a lo largo de su trayectoria y, por el otro, los sitios que en determinado momento algún miembro de ese mismo grupo familiar deseó específicamente realzar y perpetuar para el mantenimiento de su memoria. Así, la referencia a un posible panteón familiar en el monasterio de Bonaval nos demuestra que en esto, $y$ a diferencia de lo sucedido con sus casas y palacios, desaparecidos en su totalidad, los Moscoso alcanzaron un éxito notable ${ }^{61}$. Incluso llegó a circular, en época moderna, a modo de explicación la tradición de que Santo Domingo al visitar Santiago se alojó por cortesía en los palacios señoriales de la Praza do Campo ${ }^{62}$.

Sin embargo estos enterramientos de Bonaval no fueron el panteón de la familia hasta época muy tardía y de modo breve. De tal manera, aún a día de hoy una mutilada capilla de los Moscoso se conserva parcialmente en la catedral (capilla de Sancti Spiritus), lugar de reposo de los prelados, canónigos y algunos antepasados de la familia ${ }^{63}$. Al parecer, las preferencias individuales y el contexto de la muerte de otros miembros del linaje llevarían a que esta capilla no fuera el enterramiento exclusivo de la familia en el XV, comenzando por el canónigo Ruy Sánchez, que optó por enterrarse junto a su abuelo en Santa María do Camiño (García Oro y Portela Silva 2003: 85; Valdés 2011: 159). Por su parte, en el convento de Santa Clara se conservan algunas de las lápidas de las mujeres del linaje, como María Bicos, hermana de Bernal Eanes do Campo, que profesaron allí, en al menos dos de ellas campan juntas las armas de los Do Campo y, muy mutiladas, las de Moscoso ${ }^{64}$.

Por su parte, y aunque no suele destacarse, Ruy Sánchez el Tuerto quiso ser enterrado junto a su tío Bernal Eanes do Campo en San Paio de Antealtares y lo mismo hizo su hijo Rodrigo ${ }^{65}$. Es más, en 1467, Álvaro Pérez de Moscoso había pedido ser enterrado junto a su hermano, Bernal Yáñez de Moscoso, en el convento de San Francisco, mandando hacer una capilla, también el esposo de Urraca de Moscoso reposaría allí temporalmente ${ }^{66}$.

Pese a los múltiples problemas existentes en torno a la identificación y definición de los lugares de enterramiento privilegiados por la familia, parece colegirse en la mayoría de estudios que mostraron cierta predilección por Santo Domingo de Bonaval. Conviene no olvidar que algunos de los Do Campo, como otros burgueses y caballeros compostelanos, se enterraban allí desde finales del XIV y aún lo hacían a principios del XV (Manso 1982: 132-133; 1983: 81, 119; 1986: 71). Sin embargo este no era el caso de los Moscoso, de los cinco varones titulares de la casa de Moscoso a lo largo del XV cuatro se entierran en otras instituciones religiosas distintas, por ello creemos que el posible panteón de Bonaval sólo pudo alcanzar tal condición a partir del interés particular del I Conde de Altamira y de la devoción de su hermana.

61 Cendón (2012: 92-94) y Manso (1993, I: 177 y ss.). Una aportación reciente en García Rodríguez (2012) y Valdés (2011: 152); véase Chamoso (1979: 602-613).

${ }^{62}$ AHUS, Colección Blanco Cicerón, documentos en papel, 12 y Barreiro (1889: 154).

${ }^{63}$ Se conservan cuatro fragmentos descontextualizados de al menos tres sepulcros de los Moscoso: MP 417, MP 418, MP 419 y MP 420. Véanse Manso (1983: 100-103), López Ferreiro (1903, ap.: 155-159), Cendón (2000: 32-34), Fraga (2000: 172), Pardo de Guevara (2001: 75-76).

${ }^{64}$ Véanse Gimeno (1996: 153-154, 161) y Castro (1996: 269-273).

${ }^{65}$ AHUS, Clero, Mitra, leg. 133, pieza 19, ff. 1-4; AHUS, Clero, Mitra, leg. 133, pieza 20; ASPA, Condado de Altamira, 3A1/74, f. 3.

${ }^{66}$ Véase García Oro y Portela Silva (2003: 99). 
Se construye pues una memoria nueva reaprovechando los elementos ya existentes, como las tumbas de Juan do Campo y su esposa Constanza Méndez en la zona del coro, la tumba de Juana García, viuda del escudero Álvaro Fernández do Campo, la tumba de Constanza López de Moscoso y su esposo Luis Soga de Lobeira -por cierto, uno de los grandes enemigos de Ruy Sánchez de Moscoso-, la sepultura y capilla mayor de Constanza de Moscoso, esposa de Fernán Pérez de Andrade o Boo, el sepulcro de María de Moscoso, esposa de Fernán Pérez de Andrade II y la capilla y enterramiento de Urraca de Moscoso ${ }^{67}$; a ello se le añade, como foco principal, la tumba de Lope Sánchez de Moscoso "en medio de la capilla maior... delante del altar"68. Que el interés del Conde de Altamira era destacarse a sí mismo lo tenemos, además, en la prevención de su testamento de que, en caso de que se trasladase su sepultura de su de por sí poco modesta ubicación, lo hicieran a "la capilla del Arzobipo don Lope, mi tio [...] que esta sita en la Santa Iglesia de Santiago"69.

Esto es, a inicios del siglo XVI cuando el título condal y el poder de la Casa están más afianzados se decide crear un espacio propio en un lugar ya conocido por su ligera asociación al linaje y con connotaciones adecuadas, vinculado a los Do Campo, a algunas mujeres de la casa Moscoso, por cierto como símbolo también de la relación secular de los Moscoso y Andrade, que tuvo un punto álgido precisamente en esos años finales del XV (Presedo 2008: 190, 196-198, 200-202). No es un panteón de la casa, sino el lugar de reposo eterno del primer Conde de Altamira, cuya relación con Ruy Sánchez, Rodrigo, Bernal Yáñez y Álvaro Pérez no dejaba de ser la misma que lo ligaba a las Moscoso y Do Campo ya enterrados en Bonaval.

No vamos a volver a resaltar la importancia simbólica que estos lugares guardaban para el linaje y su expresión deliberada en el medio urbano. De hecho, y al margen de estos enterramientos, cabe detenerse un momento en los novelescos sucesos en torno al incómodo cadáver de la primera Condesa de Altamira puesto que se consideran un ejemplo excelente de damnatio memoriae, si los comparamos con el tratamiento del cuerpo de su esposo. Ya señalamos las implicaciones que, a nivel político, tuvo el suicidio de Aldonza. En todo caso, su cuerpo fue objeto de un extraño proceso mal conocido hasta ahora.

En primer lugar, fue enterrado en el monasterio de San Paio de Antealtares. Tal vez haya que ubicar aquí la escueta referencia de la contabilidad arzobispal que refiere una serie de hachas que "avian sobrado del enterramiento de la señora Condesa, que aya Santa gloria" (Vázquez Bertomeu 2002: 300), por lo que ha de suponerse que los Moscoso no tomaron parte activa en el mismo. Segundo, al persistir las dudas sobre su muerte, siempre según el abad, se motivó que la comunidad-que no destacaba en estos momentos precisamente por su rigurosa observancia- decidiera evitar caer en pena de excomunión absteniéndose de rezar las horas canónicas mientras aquella condesa suicida yaciese entre sus muros. Después, el cuerpo fue robado una noche y llevado a un

${ }^{67}$ La posible identificación de la tumba de Juan do Campo, como la de Vasco López de Ulloa (Pardo de Guevara 1996: 158 y ss.), aún resulta problemática (Cendón 2012); todavía parece plausible el remozado de la tumba de Juan do Campo en tiempos de Constanza de Moscoso (Manso 1993, 1: 181). Véase Núñez (1986: 35, 146-49), Sánchez Ameijeiras (1989: 431, 433), Manso (1993, 1: 178-179, 181; 2: 733 y ss.), Abreu (2000: 28), Cendón (2012) y García Rodríguez (2012: 54 y ss.).

${ }^{68}$ García Oro y Portela Silva (2003: 107). Véase una donación realizada en Bonaval por Lope Sánchez en ACS, LD, 16, f. 112.

${ }^{69}$ Pardo de Guevara (1996: 158, n.70), García Oro y Portela Silva (2003: 108). Véase AHDS, Fondo General, Bienes y Rentas de la Mitra, 3, f. 89. El interés en este lugar de enterramiento privilegiado no es exclusivo de los parientes; ya en 1487 un cardenal compostelano señaló esta capilla como tumba en caso de fallecer en Santiago (Barral 1998: 432). 
lugar desconocido, sin que sepamos si esto fue a instancias de su viudo o de su tío, opción esta que parece más probable, dado que son las fuentes episcopales las únicas que conservan alguna referencia al respecto, si bien es difícilmente comprobable puesto que nadie estaba interesado en reivindicar efectivamente la memoria de Aldonza.

El Conde de Altamira decidió acudir a Roma poco después a "hacerse perdonar" y a tratar asuntos tocantes a los beneficios eclesiásticos de sus tierras, ambas cosas le ayudarían a financiar y proteger la memoria de un linaje definitivamente encumbrado que tuvo en Compostela un papel destacado como una sombra amenazante de los arzobispos. Aunque claro está, eso es otra historia.

\section{CONCLUSIONES}

A lo largo de este sucinto análisis se ha perfilado la inclusión de la Casa de Moscoso en los principales acontecimientos políticos de la Compostela bajomedieval. No puede exagerarse este papel, los diferentes titulares van imbricándose en las tensiones inherentes a la relación entre el concello y su señor, tomando y cambiando de partido. Incluso en momentos de conflictos sociales de gran envergadura el interés general de la Casa más allá de los muros de la ciudad parece imponerse. A veces de modo contraproducente; la actuación en los prolegómenos de la guerra irmandiña en Santiago, por ejemplo, a punto estuvo de disgregar la Casa.

Desde luego, hay otros nobles intentando consolidar sus intereses en otras villas; cabe señalar a los Soutomaior en Pontevedra, Tui o Rianxo, quizás uno de los elementos definitoriosde la intervención urbana de los Moscoso es precisamente esa supeditación a los intereses territoriales. No puede hablarse en el caso expuesto de la conformación de un bando propio dentro de la ciudad favorable a los Moscoso, pero sí de una presencia activa basada en un amplio patrimonio inmueble que ha quedado claramente perfilado, una serie de propiedades que debieron marcar intensamente la topografía urbana durante el siglo XV. Este proceso culmina con la edificación en el XVI de un palacio propio acorde al título condal y al amplio patrimonio rural que lo sustentaba, aunque apenas quede huella física en la Compostela actual más allá del callejero.

Un elemento llamativo en este sentido es el tardío interés de los titulares por cultivar la memoria del linaje a través de los enterramientos. Pueden esgrimirse diversas causas: los orígenes de la Casa, su estrecha relación con los Do Campo, los abruptos cambios de titular de mediados del XV y los cambios en la relación con los diferentes prelados. Dichas causas impidieron mantener de modo coherente una capilla familiar, legando al primer Conde de Altamira una serie de enterramientos dispersos por las iglesias compostelanas poco adecuados para mantener y ostentar una imagen del poder alcanzado por el linaje; una imagen de la que, además, se eliminaron individuos, como Aldonza de Acevedo, que pudieran resultar incómodos. En todo caso, el cultivo efectivo de la memoria provocaba la elección y selección de un ámbito específico, el convento de Bonaval.

El éxito de la iniciativa condal está fuera de toda duda hasta el punto de que a día de hoy resulta extremadamente difícil mencionar la Casa de Moscoso sin aludir a la creación del Condado de Altamira.

\section{REFERENCIAS BIBLIOGRÁFICAS}

Abreu, Eduardo Manuel (2000): "Pertenencías antiguas de los /vienes, que posehían, los sseñores/ de la casa de/ Mariñô de Lovera//", El Museo de Pontevedra 54, pp. 9-55.

Aponte, Vasco de (1986): Recuento de las casas antiguas del Reino de Galicia (eds. M. C. Díaz y Díaz et alii). Santiago de Compostela: Xunta de Galicia.

BARrAl, Dolores (1998): La Coruña en los siglos XIII al XV. Historia y configuración urbana de una villa de Realengo en la Galicia Medieval. A Coruña: Fundación Barrié. 
BARreiro, Benito (1888): "Dos palabras sobre el testamento inédito de Ruy Sánchez de Moscoso", Galicia Diplomática 45, pp. 325-330.

(1889): "Las casas do Campo. Solar de los condes de Altamira”, Galicia Diplomática 20, pp. 153-156.

CARRASCO, Lorena (2015): "La venganza: raíz de la conflictividad de la nobleza medieval. Los enfrentamientos entre los Moscoso y el arzobispo Fonseca (1464-1473)", De Medio Aevo 7, pp. 27-46.

Castro, Manuel de (1996): "El Real Monasterio de Santa Clara de Santiago", en M. E. Gigirey (coord.), El Real Monasterio de Santa Clara de Santiago: ocho siglos de claridad. Santiago de Compostela: Real Convento de Santa Clara, pp. 257-274.

Chamoso, Manuel (1979): Escultura funeraria en Galicia. Ourense: Instituto de Estudios Orensanos Padre Feijoo.

Cendón, Marta (1997): "El sepulcro del arzobispo compostelano don Rodrigo de Luna en Iria Flavia", Cuadernos de Estudios Gallegos 107, pp. 203-220.

(2012): "La imagen de la mujer en el arte bajomedieval gallego", en M. García-Fernández et al. (coords.), As mulleres na historia de Galicia. Santiago de Compostela: Andavira, pp. $81-100$.

Couselo, José (1926): La guerra hermandina. Santiago de Compostela: El Eco Franciscano.

FernÁndez GonzÁLEz, Alberto (2009): "El palacio del conde de Altamira en Santiago de Compostela", Laboratorio de Arte 21, pp. 157-171.

FernÁndez Abella, David (2014): "El castillo de A Rocha Forte, un ejemplo para el estudio de la guerra bajomedieval", Roda da Fortuna. Revista Eletrônica sobre Antiguidade e Medievo $3.1 / 1$, pp. 225-256.

Fernández SuÁRez, Gonzalo Francisco (2002): La Nobleza Gallega entre los siglos XIV-XV: Los Sarmiento Condes de de Ribadavia. Santiago de Compostela: El Eco Franciscano.

Fraga, María Dolores (2000): "El arte al servicio del poderoso", en M. Cendón et al. (coords.), Arte y Poder en la Galicia de los Trastámara: La provincia de A Coruña. Santiago de Compostela: Tórculo, pp. 115-172.

Framiñán, Ana María (2004): “O título vizcondal de Fisterra no contexto da creación de títulos en Galiza na Idade Media”, Estudios de genealogía, heráldica y nobiliaria de Galicia 3, pp. 421-431.

(2005): "Notas acerca de los derechos de los laicos en las iglesias parroquiales de Galicia (s. XIII-XV)", Estudios Mindonienses 21, pp. 315-378.

Framiñán, Ana María y Xosé Antón García (2004): “Os Costela, fidalgos da Casa de Moscoso (séculos XV-XVI)", Descubrindo Deza. Anuario de Estudios e Investigación 6, pp. 145-169.

Galbán, Carlos J. (2009): "El señorío de los Moscoso y el surgimiento de la fortaleza de Altamira (Brión, A Coruña)", en A. Martínez et al. (eds.), Les senyories a la Catalunya baixmedieval (ss.XIII-XV). Hostalric: Ajuntament, pp. 145-160.

(2011): "Señor, non sejas ataúd de tus criados. Una aproximación a los afines del entorno de la casa de Moscoso (c.1411-c.1510)", Anuario de Estudios Medievales 41/1, pp. 235-272.

(2011b): "La fortaleza de Cira, un caso de construcción y destrucción del poder señorial", en S. Huerta et al. (eds.), Actas del Séptimo Congreso Nacional de Historia de la construcción. Madrid: Instituto Juan de Herrera, vol. 1, pp. 449-457. 
(2011c): “'Mejor tú que yo’. La Guerra interseñorial: batallas, asaltos y tomas de fortificaciones en la Galicia del siglo XV", Ex Novo-Revista d'Humanitats 7, pp.157-179.

(2011d): “¿Sueñan las piedras con fortalezas medievales? La heterodoxia disciplinar y las fortalezas de la Tierra de Santiago", Estrat Crític. Revista d'arqueologia 5/2, pp. 86-98.

(2013): "En torno a las modalidades de control de las fortificaciones privadas en las tierras del arzobispado de Santiago. Función e imagen de la fortificación (siglos XIV-XV)", Roda da Fortuna. Revista Eletrônica sobre Antiguidade e Medievo 2.1/1, pp. 139-143.

García Oro, José (1987): Galicia en los siglos XIV y XV. A Coruña: Fundación Barrié, 2 vols.

GARCía RodríGuEZ, Matías (2012): "Imagem e territórios das elites burguesas galegas: a escultura funerária (séculos XIV-XV)”, Cuadernos de Estudios Gallegos 125, pp. 39-63.

García de Salazar, Lope (1984): Las Bienandanzas e Fortunas (ed. A. Rodríguez). Bilbao: Diputación Foral de Vizcaya, t. 4.

GarcíA-FernándeZ, Miguel (2013): "Las élites femeninas en las ciudades gallegas de la Baja Edad Media", Mirabilia 17, pp. 337-393.

García Oro, José y María José Portela Silva (2003): La casa de Altamira durante el Renacimiento. Estudio introductorio y colección diplomática. Santiago de Compostela: El Eco Franciscano.

Gimeno, Rosa (1996): "Heráldica del Monasterio de Santa Clara”, en M. E. Gigirey (coord.), El Real Monasterio de Santa Clara de Santiago: ocho siglos de claridad. Santiago de Compostela: Real Convento de Santa Clara, pp. 151-173.

GonzÁlez, Marta (1996): El arzobispo de Santiago: una instancia de poder en la Edad Media (1150-1400). Sada: Ediciós do Castro.

Justo, María José y Manuel Lucas (1991): Fontes documentais da Universidade de Santiago de Compostela. Santiago de Compostela: Universidade / Consello da Cultura Galega.

Lema, Xosé María e Roberto Mouzo (1998): O Castelo de Vimianzo e os Moscoso de Altamira. A Coruña: Deputación Provincial.

Lojo, Fernando (1991): A Violencia na Galicia do século XV. Santiago de Compostela: Universidade.

López Carreira, Anselmo (1991): Ourense no século XV. Economía e sociedade urbana na Baixa Idade Media. Vigo: Xerais.

(1997): O pleito das fortalezas da Cidade de Ourense (1455-1456). Ourense: Museo Arqueolóxico Provincial.

- (1999): A Cidade medieval galega. Vigo: A Nosa Terra.

López Ferreiro, Antonio (1895): Fueros municipales de Santiago y de su tierra. Santiago de Compostela: Seminario Conciliar Central.

(1903): Historia de la Santa A. M. Iglesia de Santiago. Santiago de Compostela: Seminario Conciliar Central, t. 6.

(1904): Historia de la Santa A. M. Iglesia de Santiago. Santiago de Compostela: Seminario Conciliar Central, t. 7.

López DíAz, María (1997): Señorío y municipalidad. Concurrencia y conflicto de poderes en la ciudad de Santiago (siglos XVI-XVII). Santiago de Compostela: Consorcio de Santiago. 
LuCas, Manuel (1999): El archivo de San Martiño de Fóra o Pinario de Santiago de Compostela. Sada: Ediciós do Castro, 2 vols.

McKenzie, David (1984): “Alonso de Fonseca Acevedo and the Irmandiño Rising”, in R. A. Cardwell (ed.), Essays in honour of Robert Brian Tate from his colleagues and pupils. Nottingham: The University of Nottingham, pp. 59-70.

Manso, Carmen (1982): "El códice de Santo Domingo de Santiago (I)", Archivo Dominicano 3, pp. 117-164. 129.

(1983): "El códice de Santo Domingo de Santiago (II)", Archivo Dominicano 4, pp. 75 -

(1985): "El códice de Santo Domingo de Santiago (IV)”, Archivo Dominicano 6, pp. $23-55$.

76.

(1986): "El códice de Santo Domingo de Santiago (V)", Archivo Dominicano 7, pp. 59-

(1993): Arte Gótico en Galicia: los dominicos. A Coruña: Fundación Barrié, 2 vols.

Menéndez Pidal, Faustino y Eduardo Pardo de Guevara (1999): “A propósito de un nuevo sello medieval gallego. El obispo Don Gonzalo de Mondoñedo y los orígenes de la Casa de Altamira", Anuario de Estudios Medievales 29, pp. 803-834.

OliverA, César (1999): "La Galicia de Vasco de Aponte: los pleitos del arzobispo Tabera contra los linajes de la Tierra de Santiago”, En la España Medieval 22, pp. 285-315.

Pallares, M. Carmen y Ermelindo Portela (2002): “Compostela y la revuelta de los irmandiños”, en C. Fernández et al. (eds.), Universitas. Homenaje a Antonio Eiras Roel. Santiago de Compostela: Universidade, vol. I, pp. 89-110.

Pardo de Guevara, Eduardo (1996): Palos, fajas y jaqueles. La fusión de armerías en Galicia durante los siglos XIII a XVI. Lugo: Diputación Provincial.

(2000): "La Casa de Altamira y sus linajes en la Baja Edad Media. Viejas noticias y nuevos documentos", en M. Suárez (coord.), Actas do I Simposio de Historia da Costa da Morte. Cee: Concello, pp. 261-282.

(2001): "Parentesco y nepotismo. Los arzobispos de Santiago y sus vínculos familiares. Siglos XIV-XV", en R. J. Yzquierdo (coord.), Los coros de catedrales y monasterios: arte y liturgia. A Coruña: Fundación Barrié, pp. 63-119.

(2006a): "De las viejas estirpes a las nuevas hidalguías. El entramado nobiliario gallego al fin de la Edad Media", Nalgures 3, pp. 265-280.

(2006b): "Fonseca, Moscoso... e o Rei. A propósito da accidentada peregrinación de León de Rosmithal, barón de Blatna", en F. Singul (dir.), Os Capitulos da Irmandade. Peregrinación en conflito social na Galicia do século XV. Santiago de Compostela: Xunta, pp. 483-501.

(2009) “Identidad y memoria genealógica. Una aportación al estudio de la antroponimia medieval gallega", Anuario de Estudios Medievales 39/1, pp. 27-45.

PÉRICARD-MÉA, Denise (2010): “Compostelle, 1466. Le déchaînement de la violence sous les yeux de pèlerins tchèques”, en F. Foronda et al. (dirs.), Violences souveraines au Moyen Âge. Paris: PUF, pp. 165-174.

Portela, Ermelindo et al. (2004): Rocha Forte. El castillo y su historia. Santa Comba: Xunta. 
Portela, Salustiano (1957): Galicia en tiempo de los Fonsecas. Madrid: CSIC.

Presedo, Antonio (2006): "O Castelo da Rocha Forte: fortaleza a serviçio, probeito e onra de la Yglesia de Santiago”, $S C+$ a. Revista do $C O A G$ 3, pp. 58-67.

- (2008): "Los logros materiales y simbólicos de una mujer noble en Galicia a comienzos de las época moderna: Doña Violante de Andrade (c.1484-1538)", Semata 20, pp. 189-218.

RodRíGuez GonzÁLEZ, Ángel (ed.) (1984): Las fortalezas de la mitra compostelana y los irmandiños. Pontevedra: Fundación Barrié, 2 vols.

(1992): Livro do Concello de Santiago (1416-1422). Santiago de Compostela: Consello da Cultura Galega.

(1995): O Tumbo Vermello de Don Lope de Mendoza. Santiago de Compostela: IEGPS.

Rodríguez, Clara Cristela (1990): El monasterio de Dominicas de Belvís de Santiago de Compostela. Ferrol: Estudios Mindonienses.

(1993): La colección documental de Santa Clara de Santiago. Santiago de Compostela: Liceo Franciscano.

SÁnCHEZ Ameijeiras, Rocío (1989): "El arnés y el armamento del caballero medieval gallego (1350-1450)", Acta Historica et Archaeologica Mediaevalia 10, pp. 427-436.

SÁnchez, Xosé Manuel (2008): "La intervención del poder pontificio en la revuelta de 13181320 en territorio compostelano. Juan XXII y Berenguel de Landoira", Territorio, Sociedad y Poder. Revista de Estudios Medievales 3, pp. 195-208.

(2010): "Don Álvaro Sánchez de Ávila, tenente de Rocha Forte, o la nobleza gallega en la transición hacia la modernidad”, Cuadernos de Estudios Gallegos 123, pp. 91-193.

VALDÉS, Rosario (2011): "La capilla de los Neira de Luaces en la iglesia compostelana de Santa María do Camiño (ss. XVI-XIX)”, Cuadernos de Estudios Gallegos 124, pp. 149-182.

VV.AA. (1901): Colección Diplomática de Galicia Histórica: Santiago de Compostela: Tipografía Galaica.

VV.AA. (1917): Colección de Documentos Históricos (Boletín de la Academia Gallega). A Coruña: Imprenta Roel, I.

(1931): Colección de Documentos Históricos (Boletín de la Academia Gallega). A Coruña: Imprenta Roel, II.

VV.AA. (2008): De la Bohême jusqu'à Compostelle. Aux sources de l'idée d'union eropéenne. Projet du roi Georges de Podebray (1464). Récit du voyage en Europe du seigneur Léon de Rozmitál (1465-1467). Biarritz: Atlantica.

VaAmonde LoRes, César (1917): Gómez Pérez das Mariñas y sus descendientes (Apuntes Históricos y Genealógicos). A Coruña: Imprenta Roel.

VÁzQuEZ, María Jesús (1994): "Los condes de Altamira. Origen, esplendor y ocaso de la ilustre familia de los Moscoso", Estudios Mindonienses 10, pp. 195-279.

VÁzquez Bertomeu, Mercedes (2002): La Hacienda Arzobispal Compostelana. Libros de recaudación (1481-83 y 1486-1491). Santiago de Compostela: IEGPS.

Vila-Botanes, Suso (2010): A Casa de Soutomaior (1147-1532). Noia: Toxosoutos.

VILlamil, José (1873): Los pertigueros de la Iglesia de Santiago, Madrid: Imprenta y Esterotipia de Aribau. 